\title{
Photooxidation of cellulose acetate and cellobiose by the uranyl ion
}

\author{
Sofia M. Fonseca, ${ }^{a}$ Hugh D. Burrows, ${ }^{* a}$ Maria G. Miguel,,${ }^{a}$ Mohamed Sarakha ${ }^{b}$ and \\ Michèle Bolte ${ }^{b}$ \\ ${ }^{a}$ Departamento de Química, Universidade de Coimbra, 3004-535 Coimbra, Portugal \\ ${ }^{b}$ Laboratoire de Photochimie Moléculaire et Macromoléculaire, U.M.R. CNRS 6505, \\ F-63177 Aubière cedex, France
}

Received 13th November 2003, Accepted 26th November 2003

First published as an Advance Article on the web 17th December 2003

The photooxidation of cellulose acetate by uranyl nitrate in acetone solutions has been investigated. Studies of the effect of the polymer on the uranyl luminescence showed an initial increase in intensity, followed by quenching. This is interpreted in terms of competition between complexation of uranyl ions by the polymer and dynamic quenching. In the quenching region, Stern-Volmer kinetics are followed. Upon photolysis of the solution, a decrease in viscosity was observed, consistent with chain scission. However, there was no sign of formation of reduced uranium species, suggesting that they are reoxidised by molecular oxygen. Model studies were carried out with cellobiose and it was confirmed that the luminescence quenching involves both dynamic and static processes. Photolysis of aqueous solutions of cellobiose and uranyl nitrate or perchlorate led to formation of uranium(v) and a decrease in $\mathrm{pH}$. Upon interruption of photolysis, uranium(v) was seen to disproportionate. Yields of reduced uranium species were higher in degassed than aerated solutions, consistent with their oxidation by molecular oxygen in the latter case. Organic radicals were detected by electron paramagnetic resonance spectroscopy upon photolysis of cellulose acetate saturated with uranyl nitrate. The mechanism of photooxidation is suggested to involve hydrogen atom abstraction from the substrate by excited uranyl ions.

\section{Introduction}

The excited dioxouranium(VI) (uranyl) ion, $\mathrm{UO}_{2}{ }^{2+}$, is a powerful oxidant $\left(E^{\circ}=2.6 \mathrm{~V}\right) .^{1-4}$ Its photooxidation reactions have been extensively studied and a number of excellent reviews presented. ${ }^{1,2,5-10}$ A fairly detailed mechanistic understanding of these reactions is now available, with both electron-transfer and hydrogen atom-abstraction reactions occurring.,10

The interaction between the uranyl ion and polymers is of considerable importance in relation to the recovery and removal of this toxic cation from aqueous solutions. ${ }^{11,12}$ In addition, photolysis of polymers in the presence of uranyl ions may be of use both for polymer chain cleavage ${ }^{13,14}$ and photoinduced graft copolymerisation. . $^{5,15}$

We have become interested in the interaction between cellulose derivatives and the uranyl ion. Whilst the photooxidation of various small carbohydrates by $\mathrm{UO}_{2}{ }^{2+}$ has been known for a long time ${ }^{16,17}$ and reaction has been shown to proceed via formation of uranium(v), ${ }^{18}$ other mechanistic details are scarce. Upon photolysis of cotton wool saturated with uranyl perchlorate at $77 \mathrm{~K}$, electron paramagnetic resonance (EPR) spectroscopy has revealed the presence of radicals which are thought to be formed from chain cleavage of cellulose. ${ }^{19}$ Valuable hints on possible mechanisms for these processes come from studies on the photooxidation of alcohols with the uranyl ion, where hydrogen atom abstraction appears to be the dominant mechanism with primary and secondary alcohols. ${ }^{10,20}$ In the case of tertiary alcohols, photooxidation is suggested to involve mainly electron transfer. ${ }^{10,19}$

We report a study of the photooxidation of cellulose acetate by uranyl ions in both solution and a heterogeneous system. For comparison, we have also studied the photooxidation of the basic structural unit of this polymer, cellobiose (Fig. 1), by $\mathrm{UO}_{2}{ }^{2+}$.

\section{Experimental}

All reagents were of the purest grade commercially available and were used without further purification. $\beta$-D-Cellobiose was from Aldrich and cellulose acetate, with a $53.5-54.5 \%$ acetic

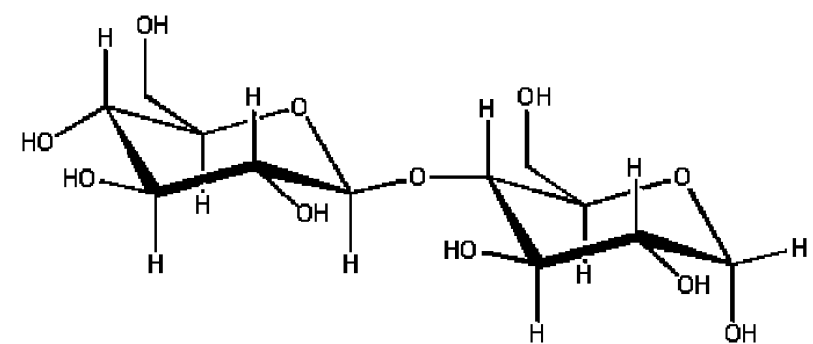

Fig. 1 The structure of cellobiose, the basic structural unit of cellulose.

acid content, was from BDH. Uranyl perchlorate was prepared by dissolving $\mathrm{UO}_{3}$ in perchloric acid and the $\mathrm{pH}$ was adjusted with potassium hydroxide solution. Solutions were prepared in doubly distilled water or in pro-analysis grade acetone, either in equilibrium with air or deaerated by bubbling nitrogen through them for $30 \mathrm{~min}$. $\mathrm{pH}$ values were adjusted by addition of dilute nitric acid.

Photolysis studies involved the use of a $125 \mathrm{~W}$ medium pressure mercury lamp with a glass filter (cut-off wavelength $320 \mathrm{~nm}$ ) to minimise direct photolysis of the polymer. Viscosity measurements were carried out in aqueous solution using an Ostwald viscometer in a thermostat bath at $25^{\circ} \mathrm{C}$. The MarkHouwink constants $K=14.9 \times 10^{-3} \mathrm{~g} \mathrm{~cm}^{-3}$ and $\alpha=0.82$ were used for solutions of cellulose acetate dissolved in acetone. ${ }^{21}$

Steady-state luminescence quenching studies were carried out using a Spex Fluorolog model 111 spectrometer. Samples were only irradiated when spectra were being recorded. Luminescence decays were measured with Applied Photophysics LKS 60 nanosecond flash photolysis apparatus using a frequencytripled pulse $(\lambda=355 \mathrm{~nm})$ from a Quanta Ray GCR 130-01 Nd:YAG laser as the excitation source. Transient absorption spectra were recorded using a standard lamp source-monochromator-photomultiplier-oscilloscope set-up, as described in detail elsewhere. ${ }^{22} \mathrm{UV} /$ visible absorption spectra were obtained using a Shimadzu UV-2100 spectrophotometer. EPR spectra were recorded with cellulose acetate samples at room temper- 
ature on a Bruker ER 200D spectrometer at $9.55 \mathrm{GHz}$ with a modulation field of $100 \mathrm{kHz}$. Samples were prepared by soaking in 0.1 or $0.01 \mathrm{M}$ uranyl nitrate solutions and were dried initially in an oven at $85^{\circ} \mathrm{C}$, and subsequently under vacuum. Light from a filtered $\mathrm{Xe}-\mathrm{Hg}$ lamp $(\lambda>335 \mathrm{~nm})$ was used to irradiate samples directly in the EPR spectrometer cavity. Although no standard was used in these measurements, signals were in the region expected for typical organic polymer radicals.

\section{Results}

\subsection{Quenching of $\mathrm{UO}_{2}{ }^{2+}$ luminescence by cellulose acetate}

The quenching of the luminescence of solutions of uranyl nitrate $(0.1 \mathrm{M})$ in acetone by cellulose acetate was studied by steady-state measurements. Excitation of the above solutions with light of $337 \mathrm{~nm}$ leads to the well-characterised ${ }^{18}$ uranyl luminescence. As can be seen in Fig. 2, there is an increase in the luminescence intensity of the uranyl ion for the lower cellulose acetate concentration, but as the concentration of the quencher increases, the uranyl luminescence decreases. This might be due to the competition between complexation of the uranyl ion in the ground state by cellulose acetate and a dynamic quenching process involving cellulose acetate and excited uranyl ions. In the former case, the lifetime of the excited uranyl ion complex might be higher, hence the increase in the uranyl luminescence intensity for the lower cellulose acetate concentrations. Increasing the concentration of the quencher leads to a decrease in the uranyl luminescence intensity due to the quenching process involving cellulose acetate and the excited uranyl ion. Support for complexation in the ground state between uranyl ions and cellulose acetate comes from UV/visible absorption spectra, where slight changes in absorbance are observed in the presence of this quencher. The uranyl ion in acetone is present mainly as $\left[\mathrm{UO}_{2}\left(\mathrm{NO}_{3}\right)_{2}\left(\mathrm{H}_{2} \mathrm{O}\right)_{2}\right]^{23}$ and the observed spectral changes can best be interpreted in terms of complexation with cellulose acetate, since the UV/visible absorption spectra are known to be strongly dependent upon the equatorial coordination geometry of the complex. ${ }^{24,25}$ Only a slight increase in luminescence, with no change in band structure, was observed on leaving a cellulose acetate sample in uranyl nitrate solution in darkness for one week, indicating that dark reactions are not important.

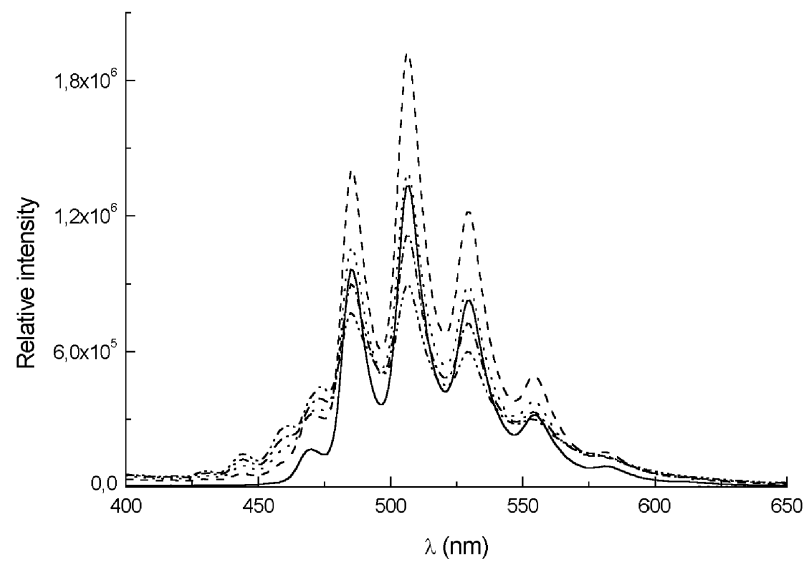

Fig. 2 Luminescence spectra of $0.1 \mathrm{M}$ solutions of uranyl nitrate in acetone in the absence $(-)$ and in the presence of $5(--), 10(\cdots)$ $15(-\cdot-)$ and $20(-\cdot-) \mathrm{mg} \mathrm{ml}^{-1}$ cellulose acetate.

For the luminescence quenching region, Stern-Volmer behaviour was observed, as shown in Fig. 3. The steady-state Stern-Volmer constant determined from the plot is $K_{\mathrm{Sv}}=$ $0.0491 \mathrm{ml} \mathrm{mg}^{-1}$.

\subsection{Photolytic studies with cellulose acetate}

Aerated solutions of uranyl nitrate $(0.01 \mathrm{M})$ and cellulose acetate $\left(10 \mathrm{mg} \mathrm{ml}^{-1}\right)$ in acetone were photolysed for $1 \mathrm{~h}$. From viscometric studies, using a Mark-Houwink relationship, a

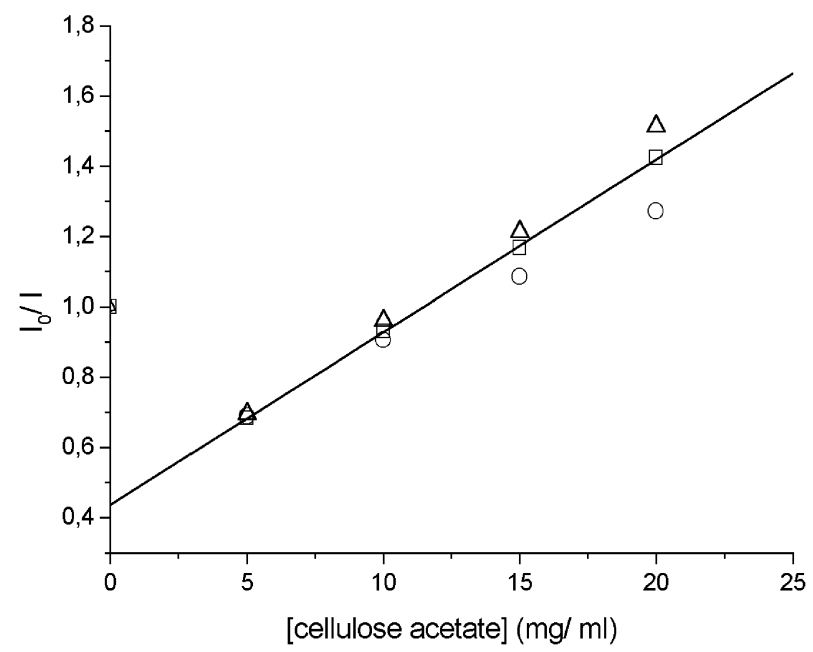

Fig. 3 Steady-state Stern-Volmer plots for the quenching of uranyl luminescence by cellulose acetate in acetone solution, with emission studied at $485(\bigcirc), 507(\triangle)$ and $530 \mathrm{~nm}(\square)$.

value of $3.80 \times 10^{4} \mathrm{Da}$ was calculated for the molecular mass of cellulose acetate before photolysis, whereas the value after photolysis was $3.21 \times 10^{4} \mathrm{Da}$. This result shows that photolysis proceeds with chain scission. However, in contrast with the behaviour in the case of sucrose ${ }^{18}$ there was no evidence of the formation of U(IV) in the UV/visible absorption spectra of the photolysed solutions. Scission of the polymeric chain could occur by hydrogen atom abstraction, ${ }^{26}$ with the formation of a polymer radical together with $\mathrm{U}(\mathrm{v})$, which would subsequently be expected to disproportionate. ${ }^{27}$ However, when $\mathrm{UO}_{2}{ }^{2+}$ is adsorbed in cellulose acetate ${ }^{28}$ the disproportionation of $\mathrm{U}(\mathrm{v})$ becomes less likely and its oxidation to $\mathrm{U}(\mathrm{VI})$ by oxygen is made easier. $^{29}$

The kinetics of chain scission were studied viscometrically. A sample was taken out every $5 \mathrm{~min}$ during a $75 \mathrm{~min}$ photolysis of an aerated solution of uranyl nitrate $(0.05 \mathrm{M})$ and cellulose acetate $\left(10 \mathrm{mg} \mathrm{ml}^{-1}\right)$ in acetone, the specific viscosity, $\eta$, of the solutions was determined and a plot of $\eta v s$. photolysis time is shown in Fig. 4. It can be seen that the specific viscosity decreases with photolysis time, in agreement with the idea that photolysis of cellulose acetate proceeds with chain scission.

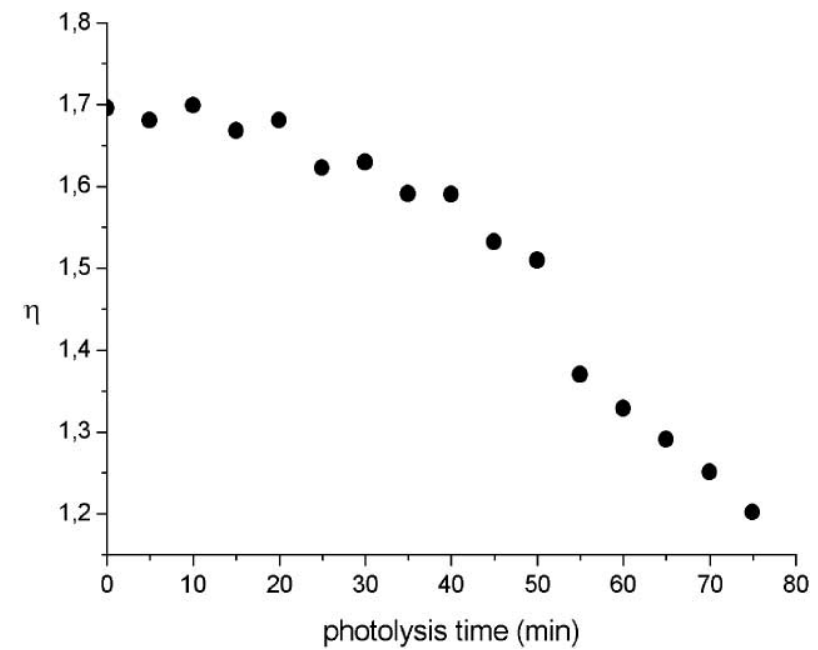

Fig. 4 Plot of specific viscosity $(\eta) v s$. photolysis time for an aerated solution of uranyl nitrate $(0.05 \mathrm{M})$ and cellulose acetate $\left(10 \mathrm{mg} \mathrm{ml}^{-1}\right)$ in acetone.

\subsection{Model studies: quenching of the $\mathrm{UO}_{2}{ }^{2+}$ excited state by cellobiose}

To obtain further information on the mechanism of the quenching process, model studies were carried out using cellobiose as substrate. These were carried out in aqueous 
Table 1 Bimolecular rate constants and Stern-Volmer constants for the quenching of $* \mathrm{UO}_{2}{ }^{2+}$ by cellobiose

\begin{tabular}{llllll}
\hline $\mathrm{pH}$ & $k_{0}{ }^{a} / 10^{5} \mathrm{~s}^{-1}$ & $k_{\mathrm{q}}{ }^{a} / 10^{8} \mathrm{M}^{-1} \mathrm{~s}^{-1}$ & $K_{\mathrm{Sv}}{ }^{b} / 10^{2} \mathrm{M}^{-1}$ & $K_{\mathrm{Sv}}{ }^{c} / 10^{2} \mathrm{M}^{-1}$ & $\left(K_{\mathrm{Sv}} / \tau\right)^{d} / 10^{8} \mathrm{M}^{-1} \mathrm{~s}^{-1}$ \\
\hline 1 & 7.03 & 1.58 & 2.24 & 4.53 & 3.04 \\
2.5 & 6.42 & 1.44 & 2.24 & 3.71 & 2.35
\end{tabular}

${ }^{a}$ Values obtained by linear regression of pseudo-first-order rate constants of $* \mathrm{UO}_{2}{ }^{2+}$ decay as a function of cellobiose concentration. ${ }^{b}$ Determined with $\lambda_{\mathrm{ex}}=355 \mathrm{~nm}$ and $\lambda_{\mathrm{em}}=510 \mathrm{~nm} .{ }^{c}$ Steady-state values determined with $\lambda_{\mathrm{ex}}=337 \mathrm{~nm}$ and $\lambda_{\mathrm{em}}=510 \mathrm{~nm} .{ }^{d}$ Using average lifetimes $(\tau)$ of $1.49(\mathrm{pH} 1)$ and $1.58 \mu \mathrm{s}$ ( $\mathrm{pH} 2.5)$, determined for $* \mathrm{UO}_{2}{ }^{2+}$ in the absence of cellobiose.

solution, since the substrate is insoluble in acetone. Following excitation of aqueous solutions of uranyl nitrate $(0.1 \mathrm{M}, \mathrm{pH}$ $2.5)$ with a frequency-tripled $\mathrm{Nd}$ :YAG laser pulse $(\lambda=355 \mathrm{~nm})$, a structured transient absorption was observed around $570 \mathrm{~nm}$. This band is assigned to the well-characterised excited $* \mathrm{UO}_{2}{ }^{2+}$ species, ${ }^{30,31}$ and the observed spectrum is presented as an inset in Fig. 5. The quenching of the luminescence of aqueous solutions of uranyl nitrate $(0.1 \mathrm{M})$ by cellobiose $\left(1 \times 10^{-3}\right.$ to $\left.1.4 \times 10^{-2} \mathrm{M}\right)$ was studied at the natural $\mathrm{pH}(\mathrm{pH} 2.5)$ and at $\mathrm{pH} 1$. Solutions were not degassed, as molecular oxygen does not affect excited uranyl ions. ${ }^{32}$ The decay of $* \mathrm{UO}_{2}{ }^{2+}$ has been shown to be strongly dependent upon the medium, temperature, excitation intensity, etc., and under some conditions is biexponential. ${ }^{20,33}$ This is probably associated with hydrolysis of the uranyl ion. However, at the relatively low $\mathrm{pH}$ and high uranyl concentration used in this study, literature data ${ }^{34}$ indicate there is no significant formation of hydrolysed uranyl species, and the excited state refers to that derived from $\left[\mathrm{UO}_{2}\left(\mathrm{H}_{2} \mathrm{O}\right)_{5}\right]^{2+} \cdot{ }^{23}$ Under these conditions, a monoexponential decay was considered for ${ }^{*} \mathrm{UO}_{2}{ }^{2+}$. The decay was faster in the presence of cellobiose and obeyed the overall rate law

$$
-\frac{\mathrm{d}\left[{ }^{*} \mathrm{UO}_{2}{ }^{2+}\right]}{\mathrm{d} t}=\left(k_{0}+k_{\mathrm{q}}[\text { cellobiose }]\right)\left[{ }^{*} \mathrm{UO}_{2}{ }^{2+}\right]
$$

Good linear plots of the pseudo-first-order rate constant as a function of cellobiose concentration were obtained at both $\mathrm{pH}$ values, from which values of $k_{0}$ and $k_{\mathrm{q}}$ were obtained (Table 1 ). Stern-Volmer plots for the quenching of the uranyl ion excited state by cellobiose are shown in Fig. 5. Steady-state data for the quenching of uranyl luminescence is also shown. The slopes for the steady-state data are higher than those corresponding to the excited-state decay data, as can be seen in Fig. 5, and the SternVolmer quenching constants $\left(K_{\mathrm{SV}}\right)$ in Table 1 . The difference can be explained in terms of some static contribution to the

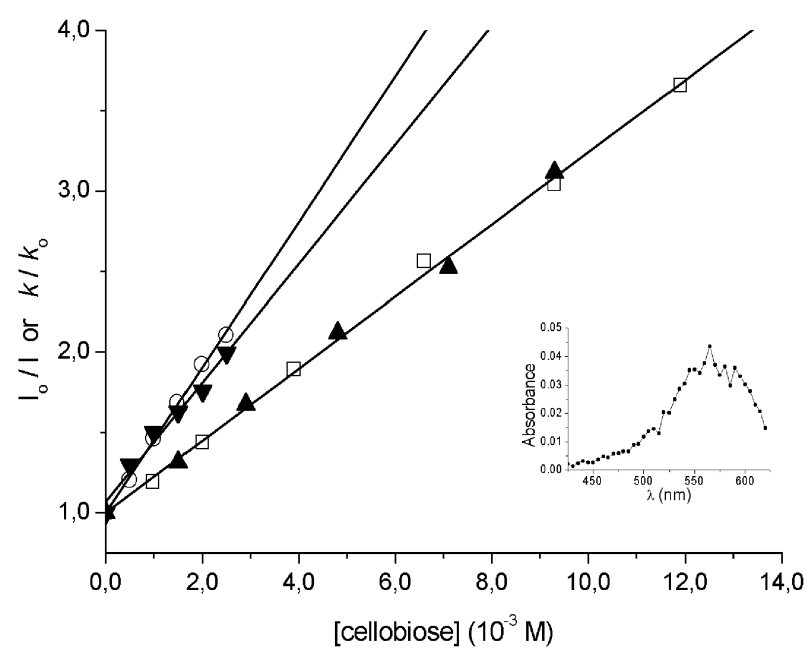

Fig. 5 Stern-Volmer plots for the quenching of the uranyl excited state by cellobiose in aqueous solution. Data shown are for the decay of uranyl luminescence at $\mathrm{pH} 1(\square)$ and $\mathrm{pH} 2.5(\mathbf{\Delta})$, and steady-state data for the quenching of uranyl luminescence at $\mathrm{pH} 1(\mathrm{O})$ and $\mathrm{pH} 2.5(\boldsymbol{\nabla})$. Inset: the transient absorption spectrum observed after excitation of an aqueous solution of uranyl nitrate $(0.1 \mathrm{M}, \mathrm{pH} 2.5)$ with a $355 \mathrm{~nm}$ laser pulse. quenching, associated with complexation in the ground state of $\mathrm{UO}_{2}{ }^{2+}$ by cellobiose. This provides further support for the suggested complexation between cellulose acetate and the uranyl ion. The Stern-Volmer quenching constants for the excited-state decay data are identical for both $\mathrm{pH}$ values, but differences are observed in the $K_{\mathrm{Sv}}$ constants corresponding to the steady-state data for the two $\mathrm{pH}$ values. Excited-state decay data is not affected by complexation in the ground-state, whereas steady-state data has contributions from dynamic and static quenching. Depending on the $\mathrm{pH}$, different dimeric and oligomeric uranium(VI) species are formed, although at $\mathrm{pH} 2.5$, only around $5 \%$ of the uranyl ions are present as the hydrolysed species $\left(\mathrm{UO}_{2}\right)_{2}(\mathrm{OH})_{2}{ }^{2+} \cdot 35$

\subsection{Photolytic studies with cellobiose}

Aerated and degassed aqueous solutions of uranyl nitrate $(0.1 \mathrm{M})$ and cellobiose $\left(2.5 \times 10^{-3} \mathrm{M}\right)$ were photolysed for $75 \mathrm{~min}$; samples were removed every $15 \mathrm{~min}$ and their UV/ visible absorption spectra recorded. Photolysis of the solutions lead to the appearance of new absorptions at $\lambda>520 \mathrm{~nm}$. However, the generation of the species giving rise to the observed spectra depends on the $\mathrm{pH}$ of the solution. Photolysis of a solution at $\mathrm{pH} 1$ yields the spectrum of uranium(IV), ${ }^{18}$ with new absorptions around 550 and $650 \mathrm{~nm}$ (Fig. 6), whereas on photolysis of solutions at $\mathrm{pH} 2.5$. the spectrum corresponds to that of uranium(v), ${ }^{36,37}$ with a new absorption band around $735 \mathrm{~nm}$ (Fig. 7). The band structure of the spectra are the same for aerated and degassed solutions, with the only difference being a slight change in the absorbance values. This will be explained below.

On photolysis, $\mathrm{H}$ atom abstraction from cellobiose by excited uranyl ions is expected to occur according to eqn. $2 \cdot{ }^{10,20} \mathrm{UO}_{2}{ }^{+}$is stable only in a very narrow $\mathrm{pH}$ range $(2-3)$ and is known to disproportionate via an acid-catalysed process (eqn. 3 ). ${ }^{27,37}$

$$
\begin{gathered}
\mathrm{UO}_{2}{ }^{2+} \stackrel{h v}{\longrightarrow}{ }^{*} \mathrm{UO}_{2}{ }^{2+} \\
* \mathrm{UO}_{2}{ }^{2+}+\mathrm{R}-\mathrm{H} \longrightarrow \mathrm{UO}_{2}{ }^{+}+\mathrm{R}^{\cdot}+\mathrm{H}^{+} \\
2 \mathrm{UO}_{2}{ }^{+}+4 \mathrm{H}^{+}=\mathrm{U}^{4+}{ }_{(\mathrm{aq})}+\mathrm{UO}_{2}{ }^{2+}+2 \mathrm{H}_{2} \mathrm{O}
\end{gathered}
$$

Thus, in the UV/visible absorption spectra recorded at $\mathrm{pH} 1$ (Fig. 6), the absorption at $735 \mathrm{~nm}$ is not observed due to the disproportionation of $\mathrm{UO}_{2}{ }^{+}$to $\mathrm{U}^{4+}$ and $\mathrm{UO}_{2}{ }^{2+}$. The results are consistent with photolysis initially producing uranium(v), which then disproportionates via an acid-catalysed reaction.

The absorbance at $735 \mathrm{~nm}$, assigned to $\mathrm{UO}_{2}{ }^{+}$, and the $\mathrm{pH}$ of the solutions were followed as a function of the time of irradiation, and plots are shown in Fig. 8. The absorbance at $735 \mathrm{~nm}$ increased rapidly, due to the formation of $\mathrm{UO}_{2}{ }^{+}$, and there was a concurrent decrease in $\mathrm{pH}$, due to the formation of $\mathrm{H}^{+}$(eqn. 2). When the irradiation was stopped for $2 \mathrm{~h}$ and the solutions kept in the dark, disproportionation of $\mathrm{UO}_{2}{ }^{+}$ occurred (eqn. 3), as evidenced by the decrease in the absorbance at $735 \mathrm{~nm}$ and the increase in $\mathrm{pH}$ of the solutions. When photolysis was reinitiated, the uranium(v) absorption at $735 \mathrm{~nm}$ and decrease in $\mathrm{pH}$ were again observed. This experiment was also performed with a solution of uranyl perchlorate $(0.1 \mathrm{M})$ and cellobiose $\left(2.5 \times 10^{-3} \mathrm{M}\right)$ to elucidate 


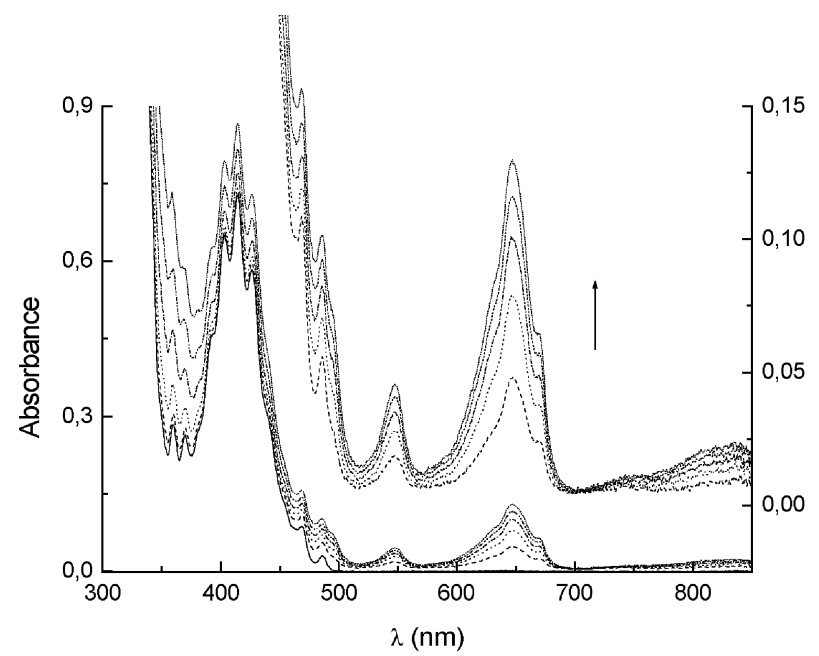

Fig. $6 \mathrm{UV} /$ visible absorption spectra of degassed aqueous solutions of uranyl nitrate $(0.1 \mathrm{M})$ and cellobiose $\left(2.5 \times 10^{-3} \mathrm{M}\right)$ at $\mathrm{pH} 1$, observed after $0,15,30,45,60$ and 75 min photolysis.

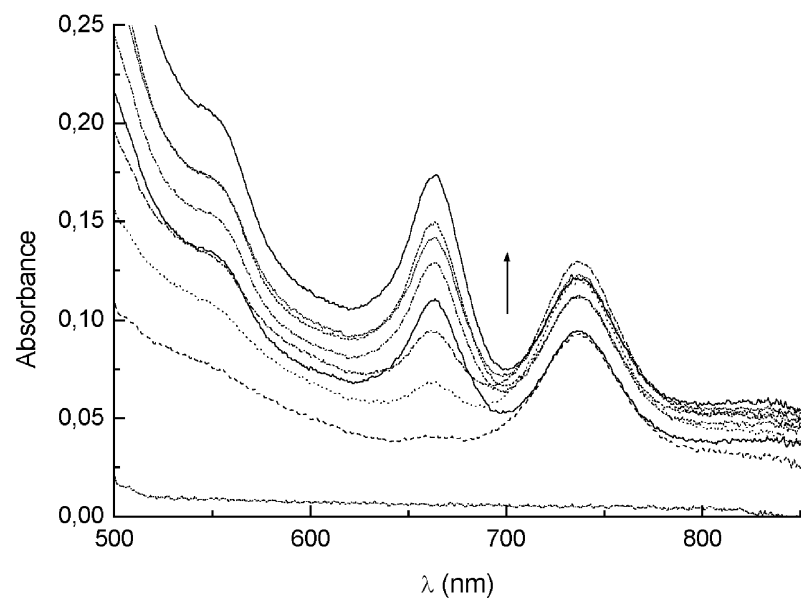

Fig. 7 UV/visible absorption spectra of aerated aqueous solutions of uranyl nitrate $(0.1 \mathrm{M})$ and cellobiose $\left(2.5 \times 10^{-3} \mathrm{M}\right)$ at $\mathrm{pH} 2.5$, observed after $0,30,60,90,120,150,180,210$ and $270 \mathrm{~min}$ photolysis.

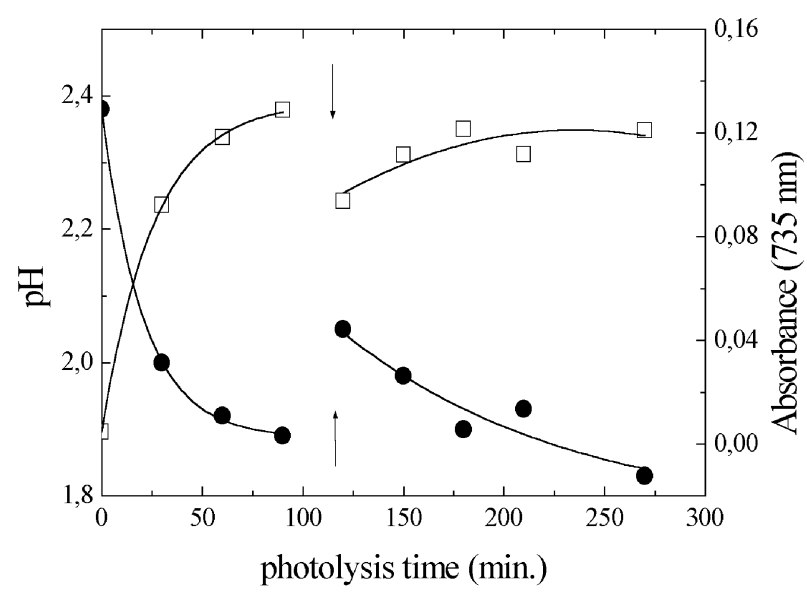

Fig. 8 Plots of $\mathrm{pH}(\mathbf{)})$ and uranium(v) absorbance at $735 \mathrm{~nm}(\square)$ as a function of time of photolysis of an aerated aqueous solution of uranyl nitrate $(0.1 \mathrm{M})$ and cellobiose $\left(2.5 \times 10^{-3} \mathrm{M}\right)$ at $\mathrm{pH} 2.5$. The arrows indicate when the point at which irradiation was stopped for $2 \mathrm{~h}$.

the role of nitrate ions in the reaction pathway. Formation of uranium(v) was again observed, with absorbance values at $735 \mathrm{~nm}$ similar to those obtained with the uranyl nitrate solution, indicating that $* \mathrm{UO}_{2}{ }^{2+}$, and not the nitrate ion, is oxidising cellobiose.

It was also observed that in the degassed solutions, the increase in the absorbance due to the $\mathrm{U}^{4+}$ and $\mathrm{UO}_{2}^{+}$species was higher than in the corresponding aerated solutions. This can be readily explained by the presence of oxygen, which oxidises $\mathrm{U}^{4+}$ and $\mathrm{UO}_{2}{ }^{+}$to $\mathrm{UO}_{2}{ }^{2+}$, according to the following reactions: ${ }^{29,38}$

$$
\begin{gathered}
2 \mathrm{U}^{4+}+\mathrm{O}_{2}+2 \mathrm{H}_{2} \mathrm{O} \longrightarrow 2 \mathrm{UO}_{2}{ }^{2+}+4 \mathrm{H}^{+} \\
2 \mathrm{UO}_{2}{ }^{+}+\mathrm{O}_{2}+2 \mathrm{H}^{+} \longrightarrow 2 \mathrm{UO}_{2}{ }^{2+}+\mathrm{H}_{2} \mathrm{O}_{2}
\end{gathered}
$$

\subsection{EPR studies}

On photolysis of cellulose acetate saturated with an aqueous solution of uranyl nitrate $(0.1 \mathrm{M})$ as a rigid medium at room temperature, an EPR signal was observed, as shown in Fig. 9. The spectra are shown after irradiation for 5 and $10 \mathrm{~min}$, and 1 min after switching off the irradiation source. From the shape of the signal at different photolysis times, there appears to be more than one radical present. The observation of an EPR signal at room temperature and its maintenance after switching off the irradiation source indicates that the radicals formed are stable. The spectra are in a similar region to those previously reported for radicals from cellulose derivatives. ${ }^{39}$ As with photolysis of uranyl salts adsorbed on pure cellulose, ${ }^{19}$ the radicals are probably formed by $\mathrm{H}$ atom abstraction from cellulose acetate by the excited uranyl ion. ${ }^{19}$ Non-selective hydrogen abstraction in cellulose, ${ }^{40}$ cellulose acetate ${ }^{41}$ and cellobiose ${ }^{41}$ has previously been suggested on the basis of EPR spectra recorded both on direct UV irradiation and photosensitised experiments.

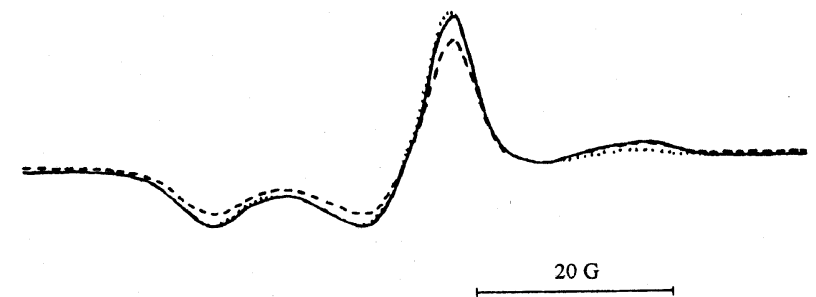

Fig. 9 EPR spectra observed on photolysis of a rigid matrix of uranyl nitrate $(0.1 \mathrm{M})$ and cellulose acetate at room temperature after irradiation for $5(--)$ and $10(-) \mathrm{min}$, and $1 \mathrm{~min}$ after switching off the irradiation source $(\cdots)$.

\section{Discussion}

The decrease in the molecular mass of cellulose acetate, as followed by viscometric studies, after photolysis of solutions of uranyl nitrate and cellulose acetate in acetone clearly shows that photolysis proceeds with chain scission. Formation of stable radicals upon photolysis of a matrix of cellulose acetate and uranyl nitrate was observed by EPR spectroscopy. These radicals are most probably formed by $\mathrm{H}$ atom abstraction from the polymeric chain by the excited uranyl ion. ${ }^{19}$ However, reduction of the uranyl ion was not observed, i.e. there was no evidence of the formation of U(v) or U(IV) in the UV/visible absorption spectra of the photolysed solutions. This is probably due to the adsorption of the uranyl ions in the cellulose acetate, which makes the disproportionation of U(v) less likely and, hence, favours its oxidation to U(VI) by molecular oxygen. ${ }^{27,29}$ Literature data indicates a non-selective $\mathrm{H}$ atom abstraction from the polymeric chain, giving rise to different types of radicals. ${ }^{40,41}$

Dynamic luminescence quenching studies of uranyl luminescence quenching by cellobiose have shown that this is a process involving a reaction between cellobiose and $* \mathrm{UO}_{2}{ }^{2+}$. Steadystate luminescence measurements under identical conditions have shown that there is some static contribution to the quenching, associated with complexation in the ground state of $\mathrm{UO}_{2}{ }^{2+}$ by cellobiose. A value of $\sim 10^{8} \mathrm{M}^{-1} \mathrm{~s}^{-1}$ was obtained for the quenching rate constant $\left(k_{\mathrm{q}}\right)$. This value is greater than those reported in the literature for uranyl luminescence quenching by aliphatic alcohols $\left(k_{\mathrm{q}} \approx 10^{6} \mathrm{M}^{-1} \mathrm{~s}^{-1}\right),{ }^{20}$ but less than the values obtained for uranyl luminescence quenching by phenols $\left(k_{\mathrm{q}} \approx\right.$ 
$\left.10^{9} \mathrm{M}^{-1} \mathrm{~s}^{-1}\right),{ }^{42}$ indicating that cellobiose is a more effective quencher than aliphatic alcohols, where hydrogen abstraction is dominant ${ }^{20}$ and a less effective quencher than phenols, where the reaction is suggested to occur by electron transfer. These results are consistent with a reaction proceeding via hydrogen atom abstraction, but with the rate being enhanced both as a result of the larger number of accessible hydrogen atoms and electronic effects due to the carbohydrate rings.

Upon photolysis of uranyl nitrate and cellobiose solutions, new absorptions assigned to $\mathrm{UO}_{2}{ }^{+}$and $\mathrm{U}^{4+}$ are observed in the UV/visible absorption spectra, with a concurrently decrease in $\mathrm{pH}$. Again, these results support $\mathrm{H}$ atom abstraction from cellobiose by excited uranyl ions according to eqn. 2. While literature data ${ }^{41}$ suggest non-selective $\mathrm{H}$ atom abstraction from cellobiose, studies on various organic substrates ${ }^{43}$ indicate hydrogen abstraction from secondary $\mathrm{C}-\mathrm{H}$ bonds is more rapid than from $\mathrm{CH}_{2}$ or $\mathrm{OH}$ groups. This suggests preferential attack at the hydrogen atoms bonded to the ring carbon atoms.

These studies indicate that photooxidation by the uranyl ion produces free radicals, and might provide a route to photoinitiated free radical graft copolymerisation of cellulose. Preliminary results support this proposition.

\section{Acknowledgements}

Financial support for the collaboration between ClermontFerrand and Coimbra by FCT and CNRS is gratefully acknowledged. One of us (S. M. F.) also thanks FCT for a scholarship.

\section{References}

1 V. Balzani, F. Bolletta, M. T. Gandolfi and M. Maestri, Bimolecular electron transfer reactions of the excited states of transition metal complexes, Top. Curr. Chem., 1978, 75, 1-63.

2 C. K. Jorgensen and R. Reisfeld, Uranyl photophysics, Struct. Bonding (Berlin), 1992, 50, 121-171.

3 H. D. Burrows, S. J. Formosinho, M. G. Miguel and F. Pinto Coelho, Quenching of the luminescent state of the uranyl ion by metal ions: evidence for an electron-transfer mechanism, J. Chem. Soc., Faraday Trans. 1, 1976, 72, 163-171.

4 M. D. Marcantonatos, Mechanism of interaction between aquometallic complexes and the photoexcited aquouranyl(VI) ion, J. Chem. Soc., Faraday Trans. 1, 1979, 75, 2252-2272.

5 E. Rabinowitch and R. L. Belford, Spectroscopy and Photochemistry of Uranyl Compounds, Pergamon, Oxford, 1964.

6 H. Gusten, Gmelin Handbook of Inorganic Chemistry, Uranium Supplement, A6, Springer-Verlag, Berlin, 1983, p. 80.

7 C. P. Baird and T. J. Kemp, Luminescence, spectroscopy, lifetimes and quenching mechanisms of excited states of uranyl and other actinide ions, Prog. React. Kinet., 1997, 22, 87-139.

8 A. B. Yusov and V. P. Shilov, Photochemistry of f-element ions, Russ. Chem. Bull., Int. Ed., 2000, 49, 1925-1953.

9 S. J. Formosinho, H. D. Burrows, M. da G. Miguel, M. E. D. G. Azenha, I. M. Saraiva, A. C. D. N. Ribeiro, I. V. Khudyakov, R. G. Gasanov, M. Bolte and M. Sarakha, Deactivation processes of the lowest excited state of $\left[\mathrm{UO}_{2}\left(\mathrm{H}_{2} \mathrm{O}\right)_{5}\right]^{2+}$ in aqueous solution, Photochem. Photobiol. Sci., 2003, 2, 569-575.

10 H. D. Burrows and T. J. Kemp, The photochemistry of the uranyl ion, Chem. Soc. Rev., 1974, 3, 139-165.

11 D. Leroy, L. Martinot, C. Jérôme and R. Jérôme, Determination of the stability constants of uranyl/ polymer complexes by differential pulse polarography, Polymer, 2001, 42, 4589-4596.

12 D. Saraydin, Y. Isikver and N. Sahiner, Uranyl binding properties of poly(hydroxamic acid) hydrogels, Polym. Bull., 2001, 47, 81-89.

13 P. E. Nielsen, C. Hiort, S. H. Sönnichsen, O. Buchardt, O. Dahl and B. Nordèn, DNA binding and photocleavage by uranyl(VI) salts, J. Am. Chem. Soc., 1992, 114, 4967-4975.

14 C. Mashavaiah and S. Verma, Reusable photonucleases: plasmid scission by a uranyl ion impregnated adenine homopolymer in the presence of visible light and sunlight, Chem. Commun., 2003, 800 801.

15 H. D. Burrows and M. da G. Miguel, Applications and limitations of uranyl ion as a photophysical probe, Adv. Colloid Interface Sci. 2001, 89-90, 485-496.

$16 \mathrm{C}$. Neuberg, Chemische umwandlungen durch strahlenarten I. Mitteilung. Katalytische reaktionen des sonnenlichtes, Biochem. Z., 1908, 13, 305-320.
17 L. J. Heidt, Quantum yields and kinetics of photosensitized production of reducing sugars from aqueous solutions of uranyl sulfate by visible and ultraviolet light, J. Am. Chem. Soc., 1939, 61, 3223-3229.

18 L. J. Heidt, Photostationary state kinetics, J. Am. Chem. Soc., 1954, 76, 5962-5968.

19 D. Greatorex, R. J. Hill, T. J. Kemp and T. J. Stone, Electron spin resonance studies of photo-oxidation by metal ions in rigid media at low temperatures. Part 4. - Survey of photo-oxidation by the uranyl ion, J. Chem. Soc., Faraday Trans. 1, 1972, 68, 2059-2076.

20 M. E. D. G. Azenha, H. D. Burrows, S. J. Formosinho and M. G. M. Miguel, Photophysics of the excited uranyl ion in aqueous solutions. Part 6. - Quenching effects of aliphatic alcohols, J. Chem. Soc., Faraday Trans. 1, 1989, 85, 2625-2634.

21 Polymer Handbook, ed. J. Brandrup and E. H. Immergaut, John Wiley \& Sons, New York, 1975

22 M. Sarakha, M. Bolte and H. D. Burrows, Electron-transfer oxidation of chlorophenols by uranyl ion excited state in aqueous solution. Steady-state and nanosecond flash photolysis studies, J. Phys. Chem. A, 2000, 104, 3142-3149.

23 M. E. D. G. Azenha, H. D. Burrows, S. J. Formosinho, M. L. P. Leitão and M. G. M. Miguel, Co-ordination behaviour of dioxouranium (VI) nitrate in water-acetone mixtures, J. Chem. Soc., Dalton Trans., 1988, 2893-2895.

24 P. Brint and A. J. McCaffery, Electronic spectra and magnetic circular dichroism of the uranyl ion. Part II. The effect of reduced symmetry on the spectra, J. Chem. Soc., Dalton Trans., 1974, $51-55$.

25 C. Görller-Walrand and S. DeJaegere, Correlation between the vibronic spectra of the uranyl ion and the geometry of its coordination, Spectrochim. Acta, Part A, 1972, 28, 257-268.

26 H. D. Burrows, S. J. Formosinho and P. M. Saraiva, Photo-oxidation of poly(vinyl alcohol) by uranyl ion: a route to photoinitiated graft copolymerisation, J. Photochem. Photobiol., A, 1992, 63, 67-73.

27 K. R. Howes, A. Bakac and J. H. Espenson, Electron-transfer reactions of uranium (V): kinetics of the uranium (V)-uranium (VI) self-exchange reaction, Inorg. Chem., 1988, 27, 791-794.

28 M. Muroi, S. Imai and A. Hamaguchi, Sorption of uranium by cellulose derivatives, Analyst, 1985, 110, 1083-1086.

29 A. Bakac and J. H. Espenson, Autoxidation of uranium(V). Catalysis and inhibition by copper ions, Inorg. Chem., 1995, 34, 1730-1735.

$30 \mathrm{H}$. D. Burrows, Electron transfer from halide ions to $\mathrm{UO}_{2}{ }^{2+}$ excitedstate ions in aqueous solution: formation and decay of dihalide radical anions, Inorg. Chem., 1990, 29, 1549-1554.

31 R. J. Hill, T. J. Kemp, D. M. Allen and A. Cox, Absorption spectrum, lifetime and photoreactivity towards alcohols of the excited state of the aqueous uranyl ion $\left(\mathrm{UO}_{2}{ }^{2+}\right)$, J. Chem. Soc., Faraday Trans. 1, 1974, 70, 847-857.

32 A. P. Darmanyan and I. V. Khudyakov, Study of luminescent forms of the uranyl ion, Photochem. Photobiol., 1990, 52, 293-298.

33 M. D. Marcantonatos, Photochemistry of the exciplex of the uranyl ion, J. Chem. Soc., Faraday Trans. 1, 1980, 76, 1093-1115.

34 R. N. Sylva and M. R. Davidson, The hydrolysis of metal ions. Part 2. Dioxouranium(VI), J. Chem. Soc., Dalton Trans., 1979, 465-471.

35 J. R. Bartlett and R. P. Cooney, Raman spectra of zeolites exchanged with uranyl (VI) cations - I. Zeolite Y, Spectrochim. Acta, Part A, 1989, 45, 541-547.

$36 \mathrm{D}$. Cohen and The preparation and spectrum of uranium (V) ions in aqueous solutions, J. Inorg. Nucl. Chem., 1970, 32, 3525-3530.

37 J. T. Bell, H. A. Friedman and M. R. Billings, Spectrophotometric studies of dioxouranium (V) in aqueous media - I. The perchlorate medium, J. Inorg. Nucl. Chem., 1974, 36, 2563-2567.

38 D. Rai, A. R. Felmy and J. L. Ryan, Uranium (IV) hydrolysis constants and solubility product of $\mathrm{UO}_{2} \cdot \mathrm{X} \mathrm{H}_{2} \mathrm{O}(\mathrm{am})$, Inorg. Chem., 1990, 29, 260-264.

39 R. E. Florin and L. A. Wall, Electron spin resonance of gammairradiated cellulose, J. Polym. Sci., Part A, 1963, 1, 1163-1173.

40 A. Merlin and J. P. Fouassier, Photochemical investigations into cellulosic materials. I. Free radical generation in cellulose by photosensitised excitation, Angew. Makromol. Chem., 1980, 86, 109121

41 A. Merlin and J. P. Fouassier, Photochemical investigations into cellulosic materials. IV. Photosensitised free radical generation in cellulose acetate and oligosaccharide compounds, Angew. Makromol. Chem., 1982, 108, 185-195.

42 M. Sarakha, M. Bolte and H. D. Burrows, The photo-oxidation of 2,6-dimethylphenol and monophenylphenols by uranyl ion in aqueous solution, J. Photochem. Photobiol., A, 1997, 107, 101-106.

43 Y. Mao and A. Bakac, Photocatalytic oxidation of toluene to benzaldehyde by molecular oxygen, J. Phys. Chem., 1996, 100, 42194223 . 